INTERNATIONAL DESIGN CONFERENCE - DESIGN 2018

https://doi.org/10.21278/idc.2018.0426

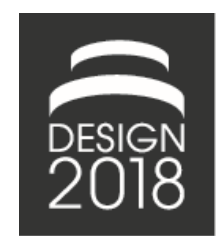

\title{
ROLE OF BIOLOGISTS IN BIOMIMETIC DESIGN PROCESSES: PRELIMINARY RESULTS
}

\author{
E. Graeff, N. Maranzana and A. Aoussat
}

\begin{abstract}
Although biomimetic design practice becomes more and more common, some methodological aspects are still under development. More especially, this article aims at dealing with biologist's role and integration during the design process and its construction. After an introduction of the context and the protocol of our experiment on a case study about the insulation of containers housing, our preliminary results will be presented. Through the use of the biomimetic tool AskNature, we will wonder about the differences between the approach of biomimetic processes by students in biology or engineering.
\end{abstract}

Keywords: biologically inspired design, biomimicry (biomimetics), design methods, interdisciplinarity, AskNature

\section{Introduction}

Biomimetic is defined as "the interdisciplinary cooperation of biology and technology or other fields of innovation with the goal of solving practical problems through the function analysis of biological systems, their abstraction into models and the transfer into and application of these models to the solution" (ISO/TC266, 2015). Over the past decades, biomimetic has established itself as one of the most promising strategies to create a boost toward innovative and environment-friendly products (Bar-Cohen, 2006; Vincent et al., 2006; Hwang et al., 2015). Many studies have evaluated such processes and shown that they allowed a greater novelty of solutions and so a greater amount of innovative products (Ahmed-Kristensen et al., 2014; Keshwani et al., 2017). However, biomimetic design process keeps facing a fundamental impediment: biologists. They potentially constitute both the greatest asset of biomimetic design and its greatest challenge. It has always been seen in interdisciplinary fields that the wealth of diversity comes with strong barriers in terms of communication and understanding between actors (Schöfer, 2015). In the case of biomimetic design, a quick review of the existing tools and processes raises the following question: where are biologists? Most of the tools are designed to be used by engineers, all processes are meant to be followed by engineers and the resulting feeling is that engineers are trying to extract biological knowledge while shortcutting biologists. This statement, even if openly provocative, is not unfounded. On account of the biomimetic intrinsic need for biological knowledge, the current strategy is to make tools, like database of biological strategies (Vincent et al., 2006; Nagel et al., 2010; Deldin and Schuknecht, 2014). So far, this process works thanks to the relative novelty of the approach and the relative low number of practitioners. The biggest database of biological strategies is AskNature which has been created in 2008 and gathers 1,671 biological strategies and 201 inspired ideas (Biomimicry Institute, 2002) and even if the database is enlarged little by little, there is a real need to hasten this process in order to represent a viable solution in the long run (Vandevenne et al., 2015). Biomimetic design teams that directly include the source of biological knowledge (i.e. biologists) are the only coherent way to consider biomimetic as a long-term design strategy (Lenau, 2009; Snell-Rood, 2016; Schöfer et al., 2018). One way of dealing with 
this methodological issue would be to call for biologists during the elaboration of the biomimetic process, leading to an interdisciplinary engineering design. This article firstly gives an overview of the global context, before it focuses on some points of reflection about engineering design of biomimetic processes. After the presentation of the problematic and the hypothesis, this article will deal with the protocol of a case study carried out on the insulation of containers homes in Ivory Coast, thanks to the above-presented biomimetic tool, AskNature. The preliminary analysis of the use of these biomimetic tools by students, with a background in engineering or in biology will be detailed to underline the differences in the approach of biomimetic processes along with the usefulness and effectiveness of databases in general. With the aim of bringing out the fundamental question of the biologist's role in the biomimetic process, this article underlines the need for an interdisciplinary approach in both biomimetic and engineering design.

\section{Context}

Through an overview of some common points between current design challenges and life's innovation mechanisms, this part addresses the question of the origin of biomimetic process and underlines its crucial need for a methodological frame.

\subsection{Modern design challenges}

Many consider the gathering of product design and sustainable development as one of the greatest modern challenges (Bourgeois, 2007; Sachs, 2015). Indeed, whereas innovation remains one of the main levers for competitiveness, decades of scientific strong warnings made politics and companies progressively realize that climate change and its impact on our society will dictate the centuries to come (IPCC, 2014). In a world where the use of energy and raw materials will have to be minimized and where waste stream will necessarily be drastically reduced, our ability to design entirely new strategies of innovation will be one of the keys to success. These expectations for the future of the modern industry create a whole new set of constraints to be solved.

Engineers often refer to design theories to solve design problems. Among these theories, which draw the current frame of design practice, a significant number is composed of problem-solving strategies that include abstraction processes (Lee et al., 2011). This part of the process aims at allowing engineers to take a step back and consider the situation with a different perspective through its formalization into models : Universal Design Theory (Grabowski et al., 1999), Synectics (Gordon, 1961), TRIZ (Altshuller, 1984), etc. Once modelized, the given set of constraints and objectives are compared with those of solved cases from the same or other scopes of practice. This analogical thinking can be extremely powerful to find inspiration but demands an important source of resolved dilemmas to reach its full efficiency. The context abovementioned, leads us to look for a prism through which design teams will be able to generate breakthrough innovations combining strong technical advantages and sustainable development. Since the survival of living beings depends on innovation guided by Nature's rules, the biomimetic approach, as the extraction of biologic strategies to create analogic innovation, can offer such a prism (Helfman Cohen and Reich, 2016). Looking at the strategies and adaptations of livings being appears to be a formidable learning tool for us to consider, as an endless reservoir of solved puzzles (Bila-Deroussy, 2015).

\subsection{Life's innovation mechanisms}

During the 3.8 billion years separating us from the apparition of life (Forterre and Gribaldo, 2007), living beings went through countless crisis, transitions and chaotic events. The ability of life to adapt, to evolve, to innovate and so to diversify is one of its main tools to build resiliency (Reynolds et al., 2012). For living entities, the main mechanisms for innovation are genetic modifications at each generation: genetic mixing through sexual reproduction, exchanges of plasmids, recombination by crossing-over, random genetic mutations and potentially epigenetic regulatory mechanisms (Griffiths et al., 2000; Richards, 2006). Those mechanisms are the source of an enormous genetic variability, and so, of a great number of possibilities, among which solutions hide. It has to be said that such mechanisms take some time since those mutations have an impact at a phenotypic scale only if they are carried by all the cells of the considered organism. This observation means that innovations are here strictly related with the generation time of the different species. Bacteria which are composed of one cell and have 
rather short generation times (ex: $5 \mathrm{~h}$ in vivo for $E$. coli) will be the source of much more innovations than pluricellular organisms with longer generation times (ex: 25 years for Loxodonta Africana, the African elephant). This phenomenon explains, for example, the technical challenges faced by the pharmaceutical industry on anti-biotics. Bacteria are much more creative and faster at doing so than researchers who are struggling to find adequate response to antibiotics resistances.

On one hand nature's innovative ability is based on creativity, thank to those genetic modifications, and on the other hand on a strong sorting, known as Darwin's theory of evolution by natural selection (Darwin, 1872; Kutschera, 2009). This two steps strategy is somewhat reminiscent of the double diamond process and of how engineers conceived the main steps of design.

Nonetheless, product design faces one huge constraint that nature does not: it has little time, little to invest and does not have much room for mistakes. Where Nature's innovation origin partially comes from inherent errors of biological mechanisms, engineers' expectations in design are about immediate quality. What is currently seeable in nature has already been selected during the past 3.8 billion years to meet the current environmental constraints and so must be considered as the present success stories of life innovation process. By looking at the living beings, we can use the results of nature's innovation mechanism while skipping the iterative and blind innovative and sorting phase. Living species are organized at multiple scales, interdependent, and especially adapted for a given environment, which means they are adapted to a given set of constraints (Nelson et al., 2007). If constraints drive innovation (Kilian, 2006; Allen, 2012), this diversity of adapted species gives us as many solutions as they are environmental conditions.

\subsection{Bio-inspiration, a wish to learn from Nature}

Bio-inspiration is not a new strategy. Nature has soon been an object of comparison and a source of inspiration during the development of antic societies (Vincent et al., 2006; Lenau, 2009) and has led to several scientific and design breakthroughs throughout history: Leonardo Da Vinci's work on flying machines inspired by birds (Richter et al., 2008), the Eiffel Tower based on bone structure (Eggermont, 2015), spiroid winglets imagined after the wingtips feathers of birds of prey (Guerrero et al., 2012), antimicrobial Sharklet ${ }^{\mathrm{TM}}$ surface mimicking shark's skin (Magyar et al., 2017), etc. From aeronautic (Bar-Cohen, 2012) to biomedical field (Boeuf, 2007; Zhang, 2012), biomimetic success stories along with the dissemination work of iconic figures, such as Janine Benyus (2002), gave bio-inspiration an international recognition. This increasing interest of the global engineering community also uncovered the lack of tools, processes and methods on bio-inspiration, leading engineers to formalize bio-inspired design process in order to systemize its use.

\subsection{The need for the formalization of biomimetic processes}

The inherent difficulty of such interdisciplinary and unframed field is firstly the communication between the different actors. To prevent any misunderstandings researchers have determined in 2015 a strict linguistic definition of the most common, and often mixed up, terms referring to the field : bioinspiration, bionic, biomimicry and biomimetic (ISO/TC266, 2015). Based on these standards, this article will focus on biomimetic (ISO/TC266, 2015).

Biomimetic processes are based on two types of approaches (Vattam et al., 2007). Either the design is conceived after a biological discovery, leading to a new product often with a high added value, based on the same standard we will call this strategy: the biology push approach (ISO/TC266, 2015). In this case, the engine of the creation process is not a problem to be solved, but an alternative or a new technology to be implemented. In the case where biomimetic is used as a problem-solving process, we will call this strategy the technology pull approach (ISO/TC266, 2015). As the core of engineering design in industry, the formalization of biomimetic methods and tools has been focusing on this problem-solving approach. Overall, models that have been created to help implement a technology pull approach are formed of the same eight main steps : Problem analysis; Abstraction of the technical problem; Transposition to biology; Identification of biological organism, function or mechanism; Choice of the organism(s) of interest; Abstraction of the biological solution(s); Transposition to technical solution(s); Implementation and tests (Fayemi et al., 2014) (Figure 1). 


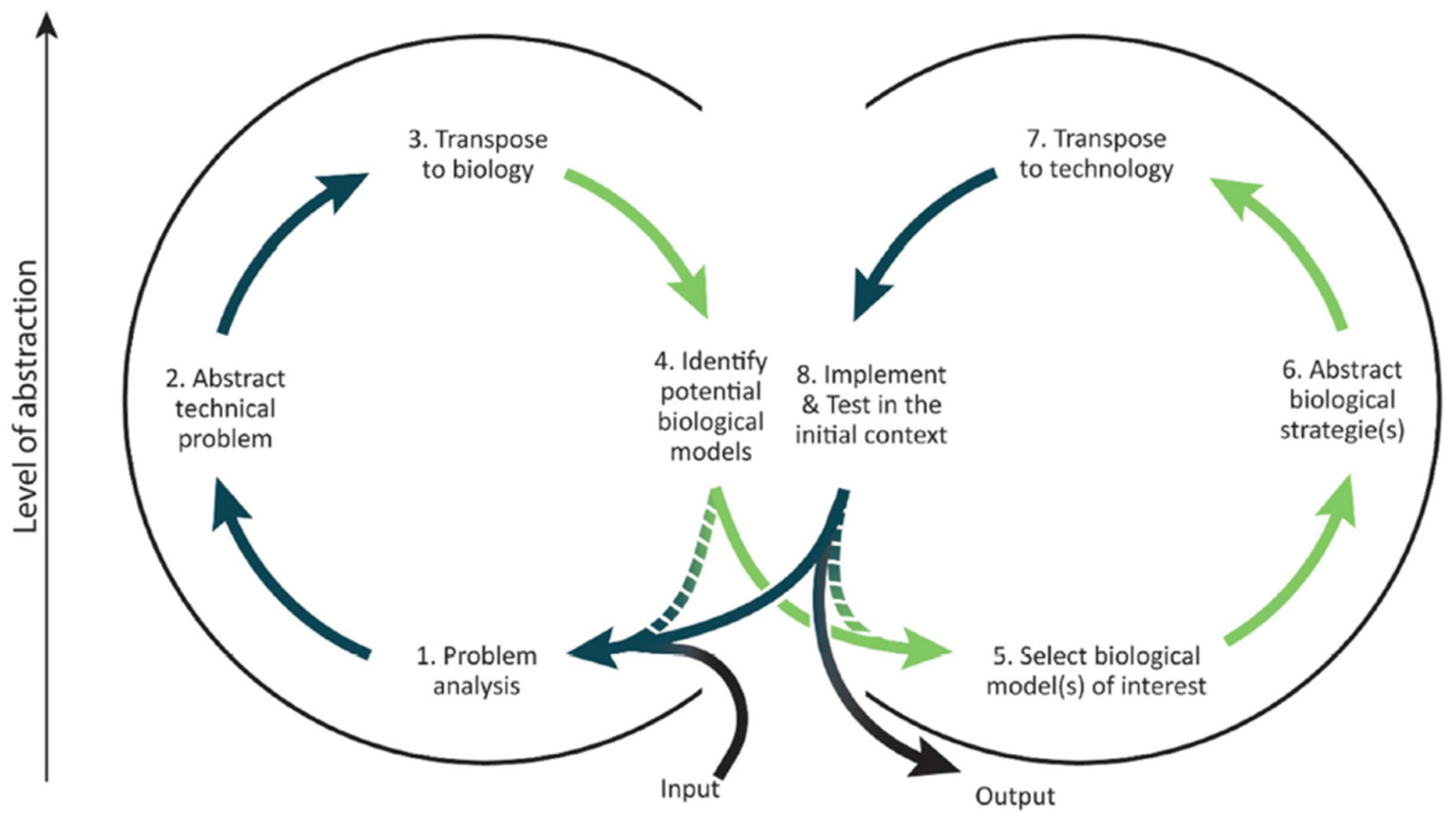

Figure 1. The unified technology pull biomimetic process from Fayemi et al. (2017)

Some of these models come from empirical analysis mixed with existing models - The procedural model of doing bionics (Lindemann and Gramann, 2004), Biomimetic design methodology (Lenau, 2009), Problem-driven analogical process (Goel et al., 2014) - but soon, the need for a new kind of tools emerged. Indeed, the lack of biological knowledge led engineers to an obvious limitation of such processes: find and extract biological strategies, functions, shapes, etc. A great number of tools have been conceived to deal with this issue, leading to the creation of tool-based methods - Idea-Inspire process (Chakrabarti et al., 2005), Biologically inspired concept generation (Nagel et al., 2010) - or to the facilitation of existing processes.

Tools used in biomimetic design have mainly three origins (Fayemi, 2016):

- engineering, like 5-Whys (Ohno, 1978) or Technical contradictions (Altshuller, 1984),

- biology, like 16 Patterns of Nature (Hoagland and Dodson, 1995) or Functional modelization (Tinsley et al., 2007),

- or have been conceived for biomimetic purposes, like SAPPhIRE (Chakrabarti et al., 2005) or BIOTRIZ (Vincent et al., 2006).

After a classification and analysis of more than 40 tools, Wanieck et al. (2017) categorized them into six kinds: database, taxonomy, thesaurus, ontology, algorithm and method. This fundamental sorting work underlined a first barrier in biomimetic development. As often in engineering design, the increasing number of tools leads the user into an unclear path as it becomes harder and harder to choose which tool to use, and in which conditions (Lahonde, 2010). To address this issue, Fayemi et al. (2014) managed to sort the different tools and determine to which steps of the global biomimetic process each of them refers. Then, Fameyi et al. (2017) analyzed tools through interdisciplinary workshops and suggested the first unified classification for biomimetic design: the BiomimeTree. More than a strict instruction manual, it aims at guiding engineers toward the appropriate tools for each step. This formalization of the biomimetic process progressively underlines a contradiction with both theoretical and practical aspects.

\section{The biologist's role in biomimetic processes}

\subsection{A paradoxical consensus}

According to the BiomimeTree model (Fayemi, 2016), transfer to biology, identification, choice of the biological organisms and abstraction of the biological strategies are the steps that have to be managed in collaboration with a biologist. Interestingly, the steps that hold the greatest numbers of 
tools are the steps of transfer (33\% in total) and the second greatest is the identification of biological model (26\%). Paradoxically, those tools are designed by engineers, using engineering references and technics and consequently appear to be made for engineers, not for biologists. Thus, it becomes clear that the global tendency is to delay biologists' intervention or even to replace biologists by tools, without dealing with their tricky integration into the biomimetic process. On the other hand, each of the 27 tools composing the BiomimeTree, needs two hours of training in average to be used properly. Therefore, tools are getting more numerous and complex to compensate for the lack of biological knowledge, which leads us to the following question: To what extent are biologists required in biomimetic design processes? And more especially, can biologists be replaced by engineers using biomimetic tools? To the best of the author's knowledge, this problematic has never been directly addressed in a scientific article, as if it was implicit that biologists are indeed necessary in spite of the inclination above-mentioned. A substantiated answer will help to set the boundaries and frame of action of both engineers and biologists, and so, the interdisciplinary steps that are required for such biomimetic processes. In order to discuss on that matter, we focused on one of the most comprehensive and complete biomimetic database (Deldin and Schuknecht, 2014; Faludi, 2017): AskNature (Biomimicry Institute, 2002).

\subsection{Hypothesis}

This article deals with the contribution of biologists in the biomimetic process. More especially, our hypothesis is that biologists cannot be replaced by engineers because tools like AskNature can be used for different goals, depending on the user's level of biological knowledge. We make the assumption that engineers with no biological background can use AskNature in order to reach a first level of abstraction, to be used as a source of inspiration for creative steps. The second part of this assumption is that a background in biology allows the user to get to a higher level of understanding, and so abstraction, of biological strategies. This hypothesis implies that a deep understanding of a biological mechanisms through these tools is hardly accessible without biological background, and that we have to consider designing tools specifically addressed to biologists, to properly help them achieve the above-mentioned steps. In order to test our assumption, we designed a case study on the insulation of container housing in Ivory Coast. For purposes of accessibility to consequent samples, our experiment compares the results obtained by students with a background in biology or engineering instead of professionals.

\section{Materials and methods}

\subsection{Materials}

The case study aims at developing an insulation for former shipping containers so that they can be turned into comfortable houses in Ivory Coast. Students had access to a short description of the case study and to a few basic data about Ivory Coast and the context of the project: climatic information (type of climate, monthly temperatures and precipitations), characteristics of the containers and of the planned village of containers, expectation of the industrial actor in terms of aesthetic.

The first tool, the Biomimicry Taxonomy, was also distributed to the participants. This open-access tool was created by the Biomimicry 3.8 Institute to transfer technical problematics from non-biological fields into requests suitable for AskNature (Baumeister, 2012).

The Biomimicry Taxonomy is constituted of three levels:

- Group, which refers to a verb (ex: protect from physical harm),

- Sub-Group, which refers to a specificity linked with the verb (ex: protect from living threats),

- Function, which refers to a more specific case in the sub-group (ex: protect from Fungi).

This multi-scale taxonomy acts as a skeleton for AskNature and enables the user to formulate requests using a common linguistic frame, directly connecting technical issues with AskNature data (Figure 2). 


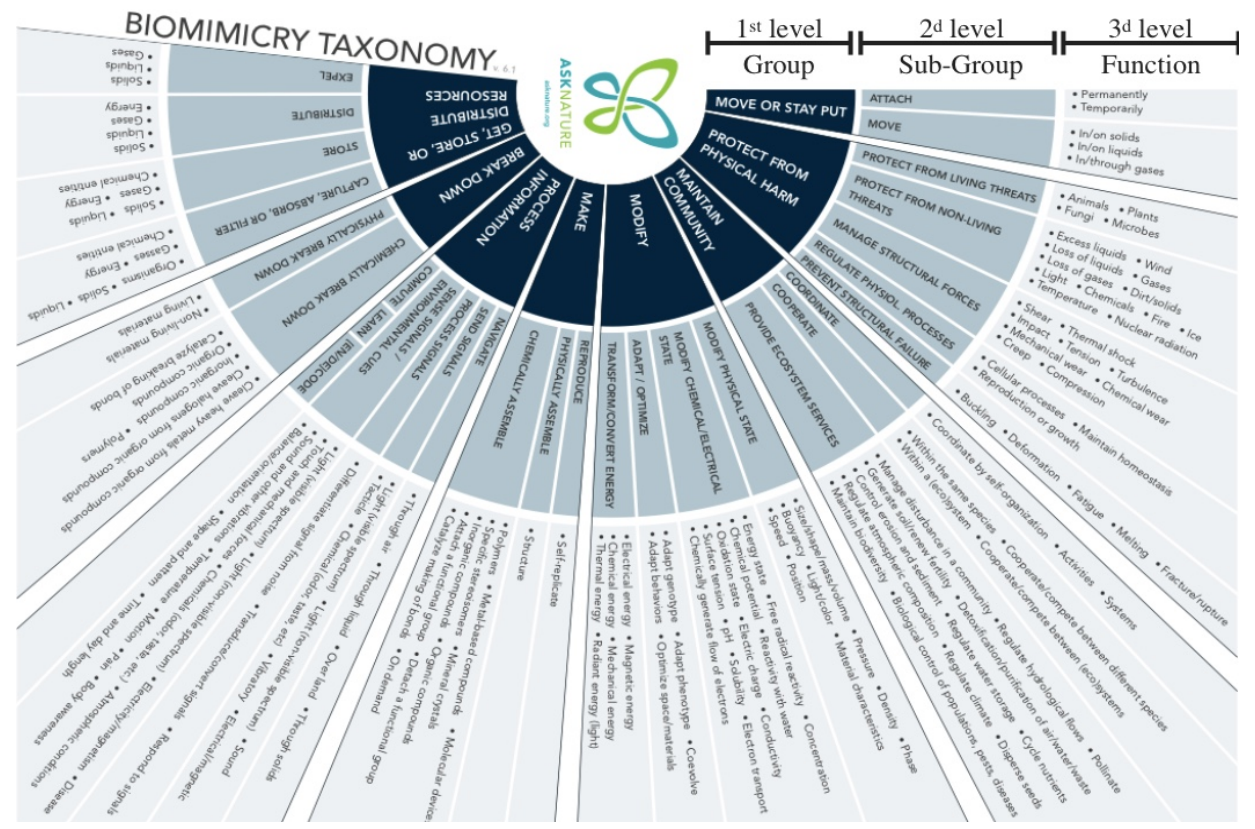

Figure 2. The Biomimicry Taxonomy

AskNature is an open-access database created by the Biomimicry 3.8 Institute (Biomimicry Institute, 2002). It lists biological organisms, strategies, functions and more generally characteristics. When the experiment took place, on November 2017, the database was composed of 1,671 biological strategies and 201 ideas inspired from biological phenomena. Those data are then made easily available through an intuitive search engine (Figure 3).

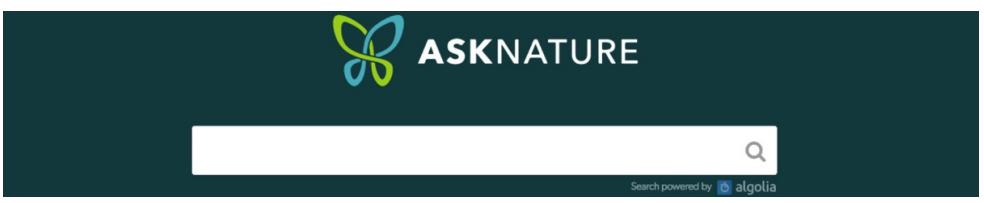

Figure 3. AskNature search engine

So far, the experiment has been conducted with a total sample of twenty students divided as explained in Table 1. The final targeted sample of this study is forty students, twenty from each background.

Table 1. Sample characteristics and repartition

\begin{tabular}{|c|c|c|c|}
\hline Background & Level of Education & Biomimetic knowledge & Number of students \\
\hline Engineering & Master degree (M2) & None & 10 \\
\hline Biology & Master degree (M1 \& M2) & None & 10 \\
\hline
\end{tabular}

Each participant had to fill in an answer sheet composed of four parts:

1. User's profile: name, background, etc. (Figure 4)

2. Results and follow-up of the biomimetic procedure: Function, Technical problems, Requests, Selected organisms, etc. (Figure 4)

\begin{tabular}{|c|c|c|c|c|c|}
\hline \multicolumn{6}{|c|}{ User profil } \\
\hline Lastname : & Name: & \multicolumn{2}{|c|}{ Domain of expertise : } & Biology & Engineering \\
\hline \multicolumn{6}{|c|}{ Results and following of the biomimetic process } \\
\hline Technical analysis & \multicolumn{2}{|c|}{ Transfer from technical problems to requests } & \multicolumn{2}{|c|}{ Results obtained on AskNature } & Transfer to technical solutions \\
\hline Functions & Technical problems & Requests & Organisms & Strategies & Technical solutions \\
\hline
\end{tabular}

Figure 4. Experiment's answer sheet 
3. Tools' evaluation (Biomimicry Taxonomy and AskNature) on a 5-points Likert scale. For each tool, five criteria, based on Nielsen's criteria about usability assessment (Nielsen, 1993), were evaluated: satisfaction, learnability, error, wealth of information (derived from Nielsen criterion "Efficiency") and precision of information (derived from Nielsen criterion "Efficiency").

4. Feedbacks from the users, one question was added: What were the hardest steps you faced?

\subsection{Methods}

So far, the experiment has been performed five times: two times with 5 students with a background in biology and three times with respectively 3,4 and 3 students with a background in industrial and design engineering. The protocol is composed of five steps and remains the same for each series.

- Presentation by the author of the biomimetic and of the container insulation case (15 min)

- Presentation by the author of the protocol, the Biomimicry Taxonomy and AskNature (15 min)

- Determination of functional constraints, technical problems and requests (30 min)

- Research of biological organisms or strategies on AskNature (30 min)

- Extraction of the biological solution into a technical one (20 min)

The authors then analysed users' answer sheets. Firstly, we focused on the number of determined functional constraints, requests and organisms. Then, to measure the understanding of biological strategies, we analyzed the "Strategies" and "Transfer to technical solutions" columns of the response sheets. Because of the short duration of the experiment, the idea was not to actually find ideas for containers insulation but rather to collect data in order to evaluate the level of understanding of the users.

To do so, a five-points scale was designed and used by the authors:

1. Not understood: Prohibitive errors in the description, strategy placed in an unsuitable context.

2. Mentioned strategy: the title of the AskNature article is quoted without any further details

3. Medium understanding: Overall understanding of the strategy and extraction of some of the scientific points explaining the biological ability.

4. Advanced understanding: extraction of most of the main scientific points leading to the strategy.

5. Complete understanding: extraction of all the crucial scientific points, abstraction into concept and ability to put the strategy back into a relevant context.

The respective repartition will be presented for each population and compared with the Mann Whitney Wilcoxon (MWW) and Chi2 test. Furthermore, in order to help the reader, the results are always presented in the text formalized as follows: (biologists results vs engineers results, type of test, p-value:).

This first analysis led us to consider a set of main tendencies that will be detailed in the next part.

\section{Results}

The results presented in this part are linked to an ongoing experiment, thus, they are to be considered as a first step of our analysis. To begin with, we will look at the feedbacks given by the users at the scale of the process.

\subsection{Feedbacks' analysis}

As expected, the feedbacks support the idea that engineers were more prepared for design procedures (Table 2).

Table 2. Table representing the mentioned steps said to be the hardest

\begin{tabular}{lccc}
\hline \multicolumn{1}{c}{ Step } & Biologists $(n=10)$ & Engineers $(n=10)$ & $p$-value \\
\hline Functions & $\mathbf{6}$ & 1 & (Chi2) $\mathbf{0 . 0 6}$ \\
\hline Technical problems & 2 & 2 & (Chi2) 1 \\
\hline Requests & 3 & 3 & $($ Chi2) 1 \\
\hline Organisms & $\mathbf{4}$ & 3 & $($ Chi2) 1 \\
\hline Biological strategies & 0 & $\mathbf{1}$ & $($ Chi2) 1 \\
\hline Technical solutions & $\mathbf{4}$ & 3 & $($ Chi2) 1 \\
\hline Total & $\mathbf{1 9}$ & 13 & (t-test) $\mathbf{0 . 0 5}$ \\
\hline
\end{tabular}


Indeed, biologists reported a significantly higher total number of difficulties (19 vs 13, t-test, p-value: 0.05) (Table 2). Unsurprisingly, the identification of the different functions was considered by most of the biologists as one of the hardest step of the whole experiment ( $60 \%$ vs $10 \%$, Chi2, p-value: 0.06$)$. On the contrary, the functional analysis is a very common procedure for engineers and so represents the first point of difference between the two populations. We are now getting into detail and study the number of results for each step of the process.

\subsection{Results for each step}

The number of identified elements appears to be higher for biologists at each step of the process (Table 3). So far, these results are not significant except for the number of identified biological strategies (8.1 vs 5.3, t-test, p-value: 0.05 ). A higher number of users should provide a stronger statistical frame to conclude on the remaining steps.

Table 3. Number of identified elements for each step

\begin{tabular}{lcccc}
\hline \multirow{2}{*}{ Step } & Biologists $(n=10)$ & Engineers $(n=10)$ & p-value $(t$-test) & Biomimetic tool \\
\cline { 2 - 3 } & mean $($ stdev $)$ & mean $($ stdev) & & \\
\hline Functions & $\mathbf{6 . 2 ( 2 . 4 )}$ & $5.2(1.0)$ & 0.25 & None \\
\hline Technical problems & $\mathbf{8 . 0 ( 3 . 7 )}$ & $6.1(1.7)$ & 0.16 & None \\
\hline Requests & $\mathbf{1 1 . 2 ( 6 . 5 )}$ & $9.7(3.8)$ & 0.54 & Taxonomy \\
\hline Organisms & $\mathbf{8 . 1 ( 3 . 9 )}$ & $6(2.3)$ & 0.19 & AskNature \\
\hline Biological strategies & $\mathbf{8 . 1 ( 3 . 6 )}$ & $5.3(2.1)$ & $\mathbf{0 . 0 5}$ & AskNature \\
\hline Technical solutions & $\mathbf{5 . 8 ( 1 . 0 )}$ & $4.4(2.8)$ & 0.17 & AskNature \\
\hline
\end{tabular}

Still, we can already point out some tendencies. Firstly, the evolution of the number of identified elements follows a classical diamond shape. The number increases from the functional analysis to the identification of requests. Then, it decreases from the selection of organisms to the design of technical solutions. Thus, the selection of organisms on AskNature appears to be the first bottleneck for both population. Secondly, we can see that the only significant difference on the number of elements is also the step where the number of elements identified by biologists ( 8.1 elements for both steps) does not decrease while the number of elements identified by the engineers does (from 6 to 5.3 elements). The extraction of the biological strategies will then be considered as the second point of difference.

\subsection{Understanding of biological phenomena}

As our hypothesis deals with the reading level of biological data, we will now focus on the understanding of biological phenomena, corresponding to the step of interest previously identified (5.2). Among the selected organisms, the understanding of biological strategies appears to be significantly higher with biologists (MWW, p-value $=0.0005$ ) explaining the second point of difference above-mentioned (5.2).
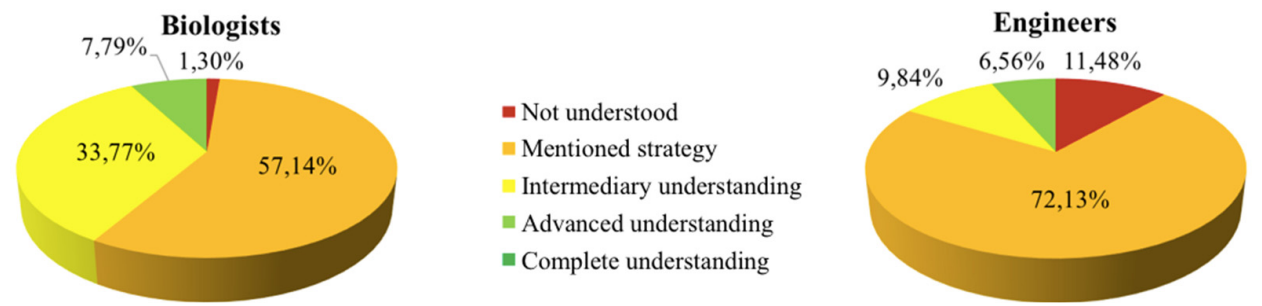

Figure 5. Understanding of the selected biological strategies

More specifically, the main difference is noticeable on the scores for the intermediary understanding class (Chi2 test, $\mathrm{p}$-value $=0.002$ ). A potential explanation is that a background in biology allows the user to understand the specific vocabulary and concepts (ex: linin, chromophore, etc.) allowing her/him to extract and reformulate the data, getting from the mentioned strategy to the intermediary understanding class. This can also be the reason for the number of not understood strategies that is higher for engineers (Chi2 
test, $p$-value: 0.03). Moreover, we can underline the close, but significantly different (Chi2 test, $\mathrm{p}$-value $=$ 0.04), proportions of strategies with an advanced understanding for each population. If the organisms of this class are similar for each population (results under analysis), it would be logical to conclude that the background of the user is not a key factor in the understanding of this given organisms. Indeed, we think that this result mainly comes from a small proportion of easy understandable and very-well described data that do not require any biological knowledge. These first results seem to confirm our hypothesis on the two reading levels of databases like AskNature. No organisms have been analysed deeply enough to be considered as completely understood. We think that this observation is mainly due to the short duration of the session, but it may also be due to a lack of information. These results on the understanding of the selected biological strategies lead us to wonder about the reasons for these differences. We thought of three possibilities, engineers were not able to understand the available information, the available information were not rich enough to allow the understanding of biological strategies by engineers, or their goal was not about a deep understanding of biological phenomena. We then studied the users' evaluation of the tools, in order to address the above-mentioned question through the feedbacks on the quality of the data.

\subsection{Tools' evaluation}

The tools' evaluation was performed by the users with a 5-points Likert scale on satisfaction, learnability, error, wealth of information and precision of information (4.2). So far, the results on the Biomimicry Taxonomy are not significantly different, as a result, we will here focus on the evaluation of AskNature. Even if the selection of the organisms is the main bottleneck of the whole process, AskNature's easy access has been underlined by the users. Interestingly, engineers gave higher scores than biologists during AskNature's evaluation, especially on its precision and wealth of information (MWW, p-value: 0.002 and 0.01 respectively) (Figure 6).
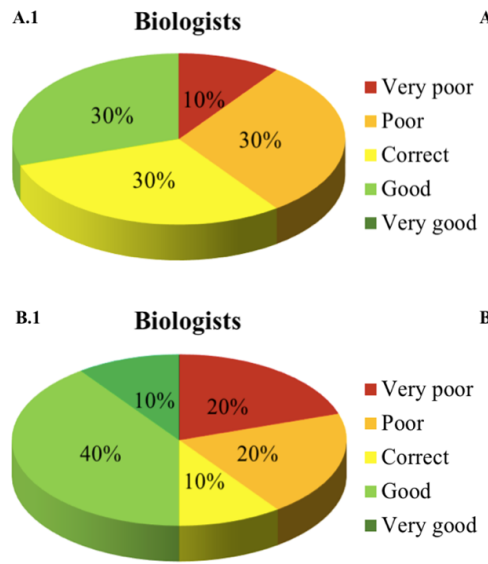

Engineers

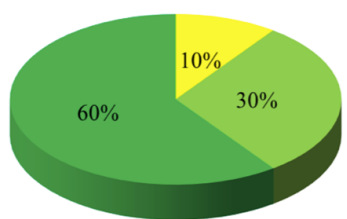

Figure 6. Evaluation of AskNature's precision (A) and wealth of information (B)

As engineers consider AskNature to be rich and precise and do not report particular difficulties for this step (Table 2), the quality of the information and their ability to understand it are not the only reasons for the low level of detail given in their results (5.3). Thus, these results support the idea that engineers and biologists do not have the same way of using the data. Hence, engineers might consider biological phenomena as a source of inspiration to be used during creativity steps rather than a source from which they can directly extract technical innovations. On the contrary, students in biology gave lower score during AskNature's evaluation but were better at analysing the biological phenomena. This pattern of results makes us think that once the functional analysis done, they focused on understanding the data in order to get to the bottom of the biological strategies. As the database does not list all known organisms and does not provide enough information to understand all the phenomena, biologists felt frustrated "the search engine restrains imagination", "the website limits, frames and offers very little ideas" and gave low score during its evaluation. Those two approaches of the biomimetic design process underline the third and maybe strongest distinction between biologists and engineers: their intrinsically specific way of reasoning, habits and insights when facing data from nature. 


\section{Conclusion}

This article aims at laying the first stone of our study on the biologist's role during biomimetic design processes. Our hypothesis was about the existence of different levels of use of biomimetic tools, such as AskNature, depending on the background of the user. We supervised biomimetic designing sessions with students having a background in either biology or engineering. The first steps of our analysis have been presented in this article and several main tendencies underlined. Firstly, the feedbacks on the global perception of the process show that biologists reported expected difficulties, especially during the functional analysis step. This first distinction is methodological, for most of the student in biology, this type of procedure was a novelty and so perceived as a difficulty. Surprisingly, in spite of their reported difficulties, biologists are the ones giving the highest number of elements at each step of the process. These results are not significant so far, but the inclinations make us wonder about the mechanism under these differences, are they due to an initial higher number of functions that is carried over to the following steps? Or do they appear at each step? The only step showing a significant difference is the identification of biological strategies, which leads us to our last point. Biologists are used to explain biological phenomena where engineers are used to solve problem through innovation. It appears reasonable to assume that the same types of behaviours will be instinctively applied in this context too. Biologists show a better understanding of biological phenomena and the results also suggest their desire to get to the bottom of the biological strategies, where engineers appear to be content with a rather low level of understanding as they gave high scores to the tool and do not report difficulties for this step. Each population deals with the biomimetic process with a different perspective, the tools' evaluation phase does not appear to be absolute but inherently linked to the expectations and the goals of the populations. Our initial assumption talks about different reading levels of the tools and these levels are not only linked with the user's abilities, they are fundamentally associated with the user's goals and way of reasoning. For the same reasons, it has to be mentioned that because of their background, biologists were already aware of the diversity of the strategies elaborated by living beings, leading to a lower wahoo effect that can partially explain the lower scores they gave during the tool's evaluation since their expectation were potentially higher on the quality of the information. So far, these results support our hypothesis on the diversity of uses and possibilities offered by these biomimetic tools, depending on the background of the user. As a consequence, they also support the idea that databases are not able to replace biologists since engineers and biologists obtain different results when using it. As obvious as it may sound, this statement aims at pushing engineering designers to consider biologists in the methodological equation of biomimetic processes. Following these preliminary results, we will pursue our work in order to offer a deeper analysis, a stronger statistical frame and try to answer the questions raised by this article. We will also detail the results obtained by the different populations to point out the specificities of each profile. By doing so, we want to justify and extrapolate the role of biologists in the biomimetic process from an engineering design point of view and with an interdisciplinary objective. The final purpose of this work will be to offer lines of reflection to stimulate the integration of biologists into biomimetic design teams through engineering design, and to optimize its role(s).

\section{References}

Ahmed-Kristensen, S., Christensen, B.T. and Lenau, T.A. (2014), "Naturally original: Stimulating creative design through biological analogies and Random images", Proceedings of the DESIGN 2014 / 13th International Design Conference, Dubrovnik, Croatia, pp. 427-436.

Allen, T.L. (2012), "Necessity is the mother of innovation: constraints and community engagement", DS 73: Proceedings of the 2nd International Conference on Design Creativity (ICDC2012), Glasgow, UK, September 18-20, 2012.

Altshuller, G. (1984), Creativity as an exact science: The theory of the solution of inventive problems, 1st ed., Gordon and Breach Science Publishers, New York.

Bar-Cohen, Y. (2006), "Biomimetics - Using nature to inspire human innovation", Bioinspiration and Biomimetics, Vol. 1 No. 1, pp. P1-P12. https://doi.org/10.1088/1748-3182/1/1/P01

Bar-Cohen, Y. (2012), "Biologically inspired technologies for aeronautics", In: Young, T. and Hirst, M. (Eds.), Innovation in Aeronautics, Woodhead Publishing, pp. 15-36. https://doi.org/10.1533/9780857096098.1.15

Baumeister, D. (2012), Biomimicry Resource Handbook: A seed bank of knowledge and best practices, 2014 ed., CreateSpace Independent Publishing Platform, Missoula. https://doi.org/10.1017/CBO9781107415324.004

Benyus, J. (2002), Biomimicry: innovation inspired by Nature, Harper Perennial. 
Bila-Deroussy, P. (2015), Systemic approach of creativity: Tools and methods to address complexity in design, $\mathrm{PhD}$ thesis, Ecole nationale supérieure d'arts et métiers - ENSAM.

Biomimicry Institute (2002), AskNature - Innovation Inspired by Nature. [online] AskNature. Available at: https://asknature.org/ (accessed: 10.11.2017).

Boeuf, G. (2007), “Océan et recherche biomédicale”, Journal de la Société de Biologie, Vol. 201 No. 1, pp. 5-12. https://doi.org/10.1051/jbio:2007001

Bourgeois, P. (2007), Les grands défis technologiques et scientifiques au XXIe siècle, Ellipses Marketing, Paris.

Chakrabarti, A., Sarkar, P., Leelavathamma, B. and Nataraju, B.S. (2005), "A functional representation for aiding biomimetic and artificial inspiration of new ideas", $A I$ EDAM, Vol. 19 No. 2, pp. 113-132. https://doi.org/10.1017/S0890060405050109

Darwin, C. (1872), The origin of species by means of natural selection, or the preservation of favoured races in the struggle for life, John Murray, London. https://doi.org/10.5962/bhl.title.61216

Deldin, J. and Schuknecht, M. (2014), “The AskNature Database: Enabling Solutions in Biomimetic Design”, In: Goel, A.K., McAdams, D.A. and Stone, R.B. (Eds.), Biologically Inspired Design, Springer, London, pp. 1728. https://doi.org/10.1007/978-1-4471-5248-4_2

Eggermont, H. (2015), "Nature-based solutions: New influence for environmental management and research in Europe", Gaia, Vol. 24 No. 4, pp. 243-248. https://doi.org/10.14512/gaia.24.4.9

Faludi, J. (2017), Golden Tools in Green Design, PhD thesis, UC Berkeley.

Fayemi, P.-E., Maranzana, N., Aoussat, A. and Bersano, G. (2014), "Bio-inspired design characterisation and its links with problem solving tools", Proceedings of the DESIGN 2014 / 13th International Design Conference, Dubrovnik, Croatia, pp. 173-182.

Fayemi, P.-E., Wanieck, K., Zollfrank, C., Maranzana, N. and Aoussat, A. (2017), "Biomimetics: Process, tools and practice", Bioinspiration and Biomimetics, Vol. 12 No. 1, p. 11002. https://doi.org/10.1088/17483190/12/1/011002

Fayemi, P.-E. (2016), Innovation par la conception bio-inspirée: proposition d'un modèle structurant les méthodes biomimétiques et formalisation d'un outil de transfert de connaissances, $\mathrm{PhD}$ thesis, Ecole nationale supérieure d'arts et métiers - ENSAM, Paris.

Forterre, P. and Gribaldo, S. (2007), "The origin of modern terrestrial life", HFSP Journal, Vol. 1 No. 3, pp. 156168. https://doi.org/10.2976/1.2759103

Goel, A.K., Vattam, S., Wiltgen, B. and Helms, M. (2014), "Information-Processing Theories of Biologically Inspired Design”, In: Goel, A.K., McAdams, D.A. and Stone, R.B. (Eds.), Biologically Inspired Design, Springer, London, pp. 127-152. https://doi.org/10.1007/978-1-4471-5248-4_6

Gordon, W.J.J. (1961), Synectics - The developmnent of creative capacity, Harper \& Row, Evanston, New York.

Grabowski, H., Lossack, R.-S., El-Mejbri, E.-F. (1999), “Towards a Universal Design Theory”, Proceedings of the 1999 CIRP International Design Seminar, University of Twente, Enschede, The Netherlands, March $24-$ 26, 1999, Springer, Dordrecht, pp. 49-56. https://doi.org/10.1007/978-94-017-1901-8_2

Griffiths, A.J., Miller, J.H., Suzuki, D.T., Lewontin, R.C. and Gelbart, W.M. (2000), An Introduction to Genetic Analysis, 7th ed., W. H. Freeman and Company. Available at: http://www.ncbi.nlm.nih.gov/books/NBK21766/.

Guerrero, J.E., Maestro, D. and Bottaro, A. (2012), "Biomimetic spiroid winglets for lift and drag control", Comptes Rendus - Mecanique, Vol. 340 No. 1-2, pp. 67-80. https://doi.org/10.1016/j.crme.2011.11.007.

Helfman Cohen, Y. and Reich, Y. (2016), Biomimetic Design Method for Innovation and Sustainability. https://doi.org/10.1007/978-3-319-33997-9

Hoagland, M. and Dodson, D. (1995), The Way Life Works, 1st ed., Crown, New York.

Hwang, J., Jeong, Y., Park, J.M., Lee, K.H., Hong, J.W. and Choi, J. (2015), "Biomimetics: Forecasting the future of science, engineering, and medicine”, International Journal of Nanomedicine, Vol. 10 No. 1, pp. 5701-5713. https://doi.org/10.2147/IJN.S83642

IPCC (2014), Climate Change 2014: Synthesis Report. Contribution of Working Groups I, II and III to the Fifth Assessment Report of the Intergovernmental Panel on Climate Change on Climate Change, IPCC, Geneva, Switzerland.

ISO/TC266 (2015), Biomimétique -Terminologie, concepts et méthodologie, International Organization for Standardization, Geneva, Switzerland. Available at: https://www.iso.org/fr/committee/652577/x/catalogue/

Keshwani, S., Lenau, T.A., Ahmed-Kristensen, S. and Chakrabarti, A. (2017), "Comparing novelty of designs from biological-inspiration with those from brainstorming", Journal of Engineering Design, Vol. 28 No. 10 12, pp. 654-680. https://doi.org/10.1080/09544828.2017.1393504

Kilian, A. (2006), "Design innovation through constraint modeling", International Journal of Architectural Computing, Vol. 4 No. 1, pp. 87-105. https://doi.org/10.1260/147807706777008993

Kutschera, U. (2009), "Charles Darwin's Origin of Species, directional selection, and the evolutionary sciences today”, Naturwissenschaften, Vol. 96 No. 11, pp. 1247-1263. https://doi.org/10.1007/s00114-009-0603-0 
Lahonde, N. (2010), Optimisation du processus de conception: Proposition d'un modèle de sélection des méthodes pour l'aide à la décision, $\mathrm{PhD}$ thesis, Ecole nationale supérieure d'arts et métiers - ENSAM, Paris.

Lee, J.S., Pries-Heje, J. and Baskerville, R. (2011), “Theorizing in Design Science Research", Proceedings of the 6th International Conference on Service-oriented Perspectives in Design Science Research, Springer-Verlag, pp. 1-16. https://doi.org/10.1007/978-3-642-20633-7_1

Lenau, T. (2009), "Biomimetics as a design methodology - Possibilities and challenges", International conference on engineering design, pp. 121-132.

Lindemann, U. and Gramann, J. (2004), "Engineering design using biological principles", International Design Conference, pp. 355-360.

Magyar, A., Arthanareeswaran, V.K.A., Soós, L., Nagy, K., Dobák, A. et al. (2017), "Does micropattern (sharklet) on urinary catheter surface reduce urinary tract infections? Results from phase I randomized open label interventional trial”, European Urology Supplements, Vol. 16 No. 3, pp. e146-e148. https://doi.org/10.1016/S1569-9056(17)30153-7

Nagel, J.K.S., Nagel, R.L., Stone, R.B. and McAdams, D.A. (2010), "Function-based, biologically inspired concept generation", AI EDAM, Vol. 24 No. 4, pp. 521-535. https://doi.org/10.1017/S0890060410000375

Nelson, D.R., Adger, W.N. and Brown, K. (2007), “Adaptation to Environmental Change: Contributions of a Resilience Framework", Annual Review of Environment and Resources, Vol. 32 No. 1, pp. 395-419. https://doi.org/10.1146/annurev.energy.32.051807.090348

Nielsen, J. (1993), Usability Engineering, 1st ed., Morgan Kaufmann, Amsterdam.

Ohno, T. (1978), Toyota Production System: Beyond Large-Scale Production, 1st ed., Productivity Press, Cambridge, Mass. https://doi.org/10.1108/eb054703

Reynolds, L.K., McGlathery, K.J. and Waycott, M. (2012), "Genetic diversity enhances restoration success by augmenting ecosystem services”, PLoS ONE, Vol. 7 No. 6, p. 338397. https://doi.org/10.1371/journal.pone.0038397

Richards, E.J. (2006), "Inherited epigenetic variation - Revisiting soft inheritance”, Nature Reviews Genetics, Vol. 7 No. 5, pp. 395-401. https://doi.org/10.1038/nrg1834

Richter, I.A. et al. (2008), Notebooks, new ed., Oxford World's Classics, Oxford University Press, New York.

Sachs, J.D. (2015), The Age of Sustainable Development, Columbia University Press. https://doi.org/10.7312/sach17314

Schöfer, M. (2015), Processes and Methods for Interdisciplinary Problem Solving and Technology Integration in Knowledge-intensive Domains, $\mathrm{PhD}$ thesis, ENSAM, Paris.

Schöfer, M., Maranzana, M., Aoussat, A., Bersano, G. and Buisine, S. (2018), "Distinct and combined effects of disciplinary composition and methodological support on problem solving in groups", Creativity and Innovation Management, Vol. 27 No. 1, pp. 102-115. https://doi.org/10.1111/caim.12258

Snell-Rood, E. (2016), "Interdisciplinarity: Bring biologists into biomimetics”, Nature, Vol. 529 No. 7586, pp. 277-278. https://doi.org/10.1038/529277a

Tinsley, A., Midha, P.A., Nagel, R.L., McAdams, D.A., Stone, R.B. and Shu, L.H. (2007), "Exploring the Use of Functional Models As a Foundation for Biomimetic Conceptual Design”, ASME 2007 International Design Engineering Technical Conferences and Computers and Information in Engineering Conference, pp. 1-15. https://doi.org/10.1115/DETC2007-35604

Vandevenne, D., Verhaegen, P.-A, Dewulf, S. and Duflou, J.R. (2015), “A scalable approach for ideation in biologically inspired design”, AI EDAM, Vol. 29 No. 1, pp. 19-31. https://doi.org/10.1017/S0890060414000122

Vattam, S., Helms, M.E. and Goel, A.K. (2007), Biologically-Inspired Innovation in Engineering Design: A Cognitive Study. [online] Graphics, Visualization and Usability Center, Georgia Institute of Technology. Available at: https://smartech.gatech.edu/handle/1853/14346 (accessed: 22.02.2018).

Vincent, J.F.V., Bogatyreva, O.A., Bogatyrev, N.R., Bowyer, A. and Pahl, A.-K. (2006), "Biomimetics: its practice and theory", Journal of The Royal Society Interface, Vol. 3 No. 9, pp. 471-482. https://doi.org/10.1098/rsif.2006.0127

Wanieck, K., Fayemi, P.-E., Maranzana, N., Zollfrank, C. and Jacobs, S. (2017), "Biomimetics and its tools", Bioinspired, Biomimetic and Nanobiomaterials, Vol. 6 No. 2, pp. 53-66. https://doi.org/10.1680/jbibn.16.00010

Zhang, G. (2012), "Biomimicry in biomedical research", Organogenesis, Vol. 8 No. 4, pp. 101-102. https://doi.org/10.4161/org.23395

Eliot Graeff, $\mathrm{PhD}$ student

Arts et Métiers ParisTech, Industrial Engineering

151 Boulevard de l'Hôpital, 75013 Paris, France

Email: eliot.graeff@ensam.eu 